University of Montana

ScholarWorks at University of Montana

10-1996

\title{
Directed Insertion of a Selectable Marker into a Circular Plasmid of Borrelia Burgdorferi
}

\author{
Patricia Rosa \\ D. Scott Samuels \\ University of Montana - Missoula, scott.samuels@umontana.edu \\ Daniel Hogan \\ Brian Stevenson \\ Sherwood Casjens \\ See next page for additional authors
}

Follow this and additional works at: https://scholarworks.umt.edu/biosci_pubs

Part of the Biology Commons

Let us know how access to this document benefits you.

\section{Recommended Citation}

Rosa, Patricia; Samuels, D. Scott; Hogan, Daniel; Stevenson, Brian; Casjens, Sherwood; and Tilly, Kit, "Directed Insertion of a Selectable Marker into a Circular Plasmid of Borrelia Burgdorferi" (1996).

Biological Sciences Faculty Publications. 4.

https://scholarworks.umt.edu/biosci_pubs/4

This Article is brought to you for free and open access by the Biological Sciences at ScholarWorks at University of Montana. It has been accepted for inclusion in Biological Sciences Faculty Publications by an authorized administrator of ScholarWorks at University of Montana. For more information, please contact scholarworks@mso.umt.edu. 


\section{Authors}

Patricia Rosa, D. Scott Samuels, Daniel Hogan, Brian Stevenson, Sherwood Casjens, and Kit Tilly 


\title{
Directed Insertion of a Selectable Marker into a Circular Plasmid of Borrelia burgdorferi
}

\author{
PATRICIA ROSA, ${ }^{1 *}$ D. SCOTT SAMUELS, ${ }^{2}$ DANIEL HOGAN, ${ }^{1}$ BRIAN STEVENSON,${ }^{1}$ \\ SHERWOOD CASJENS, ${ }^{3}$ AND KIT TILLY ${ }^{1}$ \\ Laboratory of Microbial Structure and Function, Rocky Mountain Laboratories, National Institute of Allergy and \\ Infectious Diseases, Hamilton, Montana 59840' Division of Biological Sciences, University of Montana, \\ Missoula, Montana 59812²; and Division of Molecular Biology and Genetics, Department of \\ Oncological Sciences, University of Utah Medical Center, Salt Lake City, Utah $84132^{3}$
}

Received 6 June 1996/Accepted 12 August 1996

\begin{abstract}
Studies of the biology of Borrelia burgdorferi and the pathogenesis of Lyme disease are severely limited by the current lack of genetic tools. As an initial step toward facile genetic manipulation of this pathogenic spirochete, we have investigated gene inactivation by allelic exchange using a mutated borrelial gyrB gene that confers resistance to the antibiotic coumermycin $A_{1}$ as a selectable marker. We have transformed $B$. burgdorferi by electroporation with a linear fragment of DNA in which this selectable marker was flanked by sequences from a native borrelial 26-kb circular plasmid. We have identified coumermycin $A_{1}$-resistant transformants in which gyrB had interrupted the targeted site on the 26 -kb plasmid via homologous recombination with the flanking sequences. Antibiotic resistance conferred by the mutated gyrB gene on the plasmid is dominant, and transformed spirochetes carrying this plasmid do not contain any unaltered copies of the plasmid. Coumermycin $A_{1}$ resistance can be transferred to naive $B$. burgdorferi by transformation with borrelial plasmid DNA from the initial transformants. This work represents the first example of a directed mutation in B. burgdorferi whereby a large segment of heterologous DNA $(\mathrm{gyrB})$ has been inserted via homologous recombination with flanking sequences, thus demonstrating the feasibility of specific gene inactivation by allelic exchange.
\end{abstract}

Borrelia burgdorferi is maintained in nature through an infectious cycle between wild mammals and ticks (25). Lyme disease, the most common arthropod-borne disease in the United States, is acquired when an infected tick feeds upon a human and transmits $B$. burgdorferi $(8,20,52)$. There are currently very few genetic tools with which to study the biology of $B$. burgdorferi and the pathogenesis of Lyme disease. To date, there are no descriptions of any phage or plasmid vectors that can be used to efficiently introduce recombinant DNA into borreliae. Transformation of $B$. burgdorferi by electroporation was only recently achieved (47); those experiments provided definitive evidence for homologous recombination between exogenous DNA introduced by electroporation and related sequences on the chromosome. In these transformations, a segment of a chromosomal gene was replaced by donor DNA that differed by only a small (2-bp) mismatch.

$B$. burgdorferi has an unusual genome composed of a linear chromosome $(6,11,15,16)$ and multiple linear and circular plasmids $(2,5,17,19,50,54)$. It has been proposed that these various DNA molecules represent components of a segmented genome and that the distinction between plasmid and chromosome may not be relevant to borreliae $(4,7,16)$. Genes encoding a number of different proteins have been cloned and mapped to the chromosome or plasmids $(10,11,12,15)$. Cellular localization, pattern of expression, and putative function have been determined for a number of these proteins. However, a definitive understanding of the roles that any of these gene products or genomic components play in the spirochete, their essential or dispensable nature, or their significance to

\footnotetext{
* Corresponding author. Mailing address: Rocky Mountain Laboratories, 903 S. 4th St., Hamilton, MT 59840. Phone: (406) 363-9209. Fax: (406) 363-9204. Electronic mail address: patricia_rosa@nih.gov.
}

the infectious cycle or disease requires the ability to genetically manipulate the spirochete.

We would like to investigate the potential role of genes located on a 26-kb circular plasmid (cp26) of B. burgdorferi in environmental sensing and adaptation to the tick vector and mammalian host. All $B$. burgdorferi isolates analyzed contain cp26 $(26,28,53)$. Genes carried by cp26 include those encoding the differentially synthesized outer surface protein $\mathrm{C}$ $(\operatorname{osp} C)(28,44,49)$, the purine biosynthetic enzymes GMP synthetase (guaA) and IMP dehydrogenase (guaB) (30), and a homolog of the peptide-binding component of the oligopeptide permease system (opp $A)(17 \mathrm{a})$. OspC appears on the surface of spirochetes in ticks following a blood meal but preceding transmission to the mammal (49). GMP synthesis is probably essential in mammals but not in ticks (30). In other bacteria, OppA can be a receptor for peptide pheromones that signal adaptive responses to environmental conditions $(22,27$, $34,39,40,55)$. Given this information, each of these gene products, and perhaps genes located elsewhere on the $26-\mathrm{kb}$ plasmid, may play an essential role in the adaptation of B. burgdorferi to either the tick or the mammalian environment or may facilitate transmission between these two hosts. To study the functions of these and other genes in B. burgdorferi, we have undertaken to develop a method for specific gene inactivation.

B. burgdorferi variants that are resistant to the DNA gyrase inhibitor coumermycin $\mathrm{A}_{1}$ (i.e., are $\mathrm{Cou}^{\mathrm{r}}$ ) have been isolated (48), and the mutations have been mapped to the $g y r B$ gene (47). With the long-term goal of inactivating specific genes by allelic replacement, our initial aim was to insert a copy of the B. burgdorferi gyrB gene that confers $\mathrm{Cou}^{\mathrm{r}}\left(\mathrm{gyr} \mathrm{B}^{\mathrm{r}}\right)$ into a noncoding site on cp26. We chose this approach for several reasons. First, to demonstrate the feasibility of the technique, we wanted to begin with a presumably nonessential site to ensure that there was no counterselection against the desired insertion. Second, the transformed spirochetes would have both a 
TABLE 1. Coumermycin $A_{1}$ sensitivity of gyrB gene products from strains used in this study

\begin{tabular}{lcl}
\hline \multicolumn{1}{c}{ Strain $^{a}$} & Chromosomal gyrB & cp26 gyr $B^{b}$ \\
\hline wt B31 & Sensitive & - \\
B31-NGR & Resistant & - \\
B31-67 & Sensitive & Resistant \\
B31-3 & Sensitive & Resistant \\
B31-9 & Resistant & - \\
\hline
\end{tabular}

${ }^{a}$ wt B31 is the uncloned high-passage-number coumermycin $\mathrm{A}_{1}$-susceptible strain from which clones B31-NGR, $-3,-9$, and -67 were derived by transformation. The $50 \%$ inhibitory concentration for wt B31 is $0.04 \mu \mathrm{g}$ of coumermycin $\mathrm{A}_{1}$ per $\mathrm{ml}(48)$.

${ }^{b}$-, absence of $\operatorname{gyr} B^{\mathrm{r}}$ on cp26. Where present, the $\operatorname{gyr} B^{\mathrm{r}}$ gene is located between the $3^{\prime}$ ends of the oppA and guaB genes.

wild-type (wt) (chromosomal) and mutated (plasmid) copy of the gyrB gene, which would render them heterozygous for the B subunit of DNA gyrase and could affect DNA supercoiling (31). Insertion of gyrB into a noncoding site would serve as a control for possible pleiotropic effects of altered supercoiling in subsequent gene inactivation experiments. Finally, we chose gyr $B^{\mathrm{r}}$, despite this and other potential shortcomings, because it was the only antibiotic resistance marker for which there were data demonstrating a selectable phenotype in $B$. burgdorferi $(47,48)$. Previous attempts to transform $B$. burgdorferi with other antibiotic resistance markers have been unsuccessful (56).

In this report, we describe targeted insertion of $\operatorname{gyr} B^{\mathrm{r}}$ into cp26. This represents the first demonstration of directed mutation in B. burgdorferi whereby a large segment of heterologous DNA encoding a selectable marker has been inserted via homologous recombination with flanking sequences, thus demonstrating the feasibility of specific gene inactivation by allelic exchange.

\section{MATERIALS AND METHODS}

Bacterial strains and DNA. B. burgdorferi strains used in this study are listed in Table 1. Spirochetes were grown in liquid BSK-H medium (Sigma, St. Louis, Mo.) at $34^{\circ} \mathrm{C}$ (1). The protocol for plating B. burgdorferi in solid medium (24) was modified as follows: spirochetes were plated within a layer of top agarose rather than on the surface, and plates were incubated at $35^{\circ} \mathrm{C}$ in a humidified $1 \% \mathrm{CO}_{2}$ tissue culture incubator rather than in a candle jar $(35,36)$. wt B31 (ATCC 35210 ) is a high-passage-number, noninfectious, uncloned B. burgdorferi sensu strictu prototype strain, originally isolated from a tick collected on Shelter Island, N.Y. (8). Cou $^{\mathrm{r}}$ clone B31-NGR was derived from wt B31 by transformation and contains the following mutations in $\mathrm{gyrB}$ that together confer high-level $\mathrm{Cou}^{\mathrm{r}}$ : asparagine 102 to aspartate (N102D), glycine 104 to aspartate (G104D), and arginine 133 to isoleucine (R133I) (46a). The donor DNA containing these mutations was created by PCR with overlapping primers that encoded the N102D and G104D mutations, using DNA from an R133I Cou ${ }^{\mathrm{r}}$ transformant
(47) as the template. $\mathrm{Cou}^{\mathrm{r}}$ clones B31-3, -67 , and -9 were derived from wt B31 by transformation with recombinant plasmid pKK58 (described below), which contains a copy of the $g y r B^{\mathrm{r}}$ gene from B31-NGR.

Cloning. The gyrB ${ }^{\mathrm{r}}$ gene of B31-NGR was amplified by PCR $(32,45)$ with primers $\mathrm{U} 178 \mathrm{~F}+B g l \mathrm{II}$ and $1905 \mathrm{R}+B c l \mathrm{I}$ (Table 2$)$. This fragment extends from 178 nucleotides upstream of the gyr $B$ start codon to the stop codon at the end of the gene; the $5^{\prime}$ end of this fragment is 11 nucleotides from the first codon of the divergently transcribed $d n a A$ gene as described by Saint Girons et al. (45a) (corresponding to nucleotide 1320 of GenBank accession number U04527) and presumably includes the $g y r B$ promoter. This fragment was digested with restriction enzymes $B g l \mathrm{II}$ and $B c l \mathrm{I}$ and ligated into $B g l \mathrm{II}$-digested clone pDH63, a genomic clone isolated from a $B$. burgdorferi B31 DNA library constructed in Lambda ZapII (Stratagene, La Jolla, Calif.) (30), whose 3.5-kb insert is derived from cp26 and spans the opp $A$ and guaB genes (17a). The resulting plasmid, pKK58, which contains a complete copy of gyr $B^{\mathrm{r}}$ inserted between the $3^{\prime}$ ends of opp $A$ and guaB, is diagrammed in Fig. 1A. There are approximately 1.75 and 1.4 $\mathrm{kb}$ of cp 26 sequence flanking the $5^{\prime}$ and $3^{\prime}$ ends, respectively, of $g y r B^{\mathrm{r}}$. pKK58 was digested with $P v u \mathrm{I}$ to inactivate the ampicillin resistance gene before transformation into $B$. burgdorferi. Restriction enzymes were obtained from New England Biolabs (Beverly, Mass.) and used according to the supplier's recommendations.

Transformation. Preparation of competent borreliae, electroporation, and plating of spirochetes were done as previously described $(46,47)$, with the following modifications: after electroporation and 24-h incubation in liquid medium without antibiotic, spirochetes were plated in the presence of $0.5 \mu \mathrm{g}$ of coumermycin $\mathrm{A}_{1}$ (Sigma) per $\mathrm{ml}$ and incubated at $35^{\circ} \mathrm{C}$ in a humidified $1 \% \mathrm{CO}_{2}$ environment. All electroporations were done with equivalent aliquots of the same preparation of frozen, competent $B$. burgdorferi and $1 \mu \mathrm{g}$ of DNA. The final volume of the transformed culture was $10 \mathrm{ml}$ and contained approximately $10^{8}$ bacteria per $\mathrm{ml}$ at the time of plating. DNA for electroporation was resuspended in distilled water at a concentration of approximately $1 \mathrm{mg} / \mathrm{ml}$, and $1 \mu 1(1 \mu \mathrm{g})$ was used per electroporation. Colonies began to appear 5 to 7 days after plating; the total number of colonies was determined approximately 14 days after plating. The transformation frequency represents the total number of $\mathrm{Cou}^{\mathrm{r}}$ colonies per $\mu \mathrm{g}$ of donor DNA per $10^{9}$ viable bacteria following electroporation. We note that neither the DNA nor the competent bacteria are in excess under these transformation conditions; increasing either of these components in the electroporation results in more $\mathrm{Cou}^{\mathrm{r}}$ transformants. The amount of the culture plated varied with experiments but was generally 0.01 to $0.5 \mathrm{ml}$ per plate. We found significant inhibition of colony formation when more than $1 \mathrm{ml}$ of the $10-\mathrm{ml}$ transformed culture was used per plate (the medium turned yellow with time, indicative of bacterial growth, but individual colonies were not visible). We believe that this difference from the previous transformation and plating results, in which the entire transformed culture was concentrated and plated (47), is probably due to the fact that our competent bacteria were prepared from a denser culture, which resulted in more bacteria per aliquot. This is also consistent with obtaining approximately 10 -fold more transformants per microgram of DNA than in previous experiments. We did not note a decrease in the ability to transform $B$. burgdorferi with increasing density of the initial culture from which the competent bacteria were prepared.

PCR. Oligonucleotide primers used for PCR are described in Table 2 and specified in individual experiments. PCR-amplified fragments used in cloning and transformation and as probes were produced in a TC1 DNA Thermal Cycle (Perkin Elmer/Applied Biosystems, Foster City, Calif.); PCR conditions for fragment production were 25 cycles of $94^{\circ} \mathrm{C}$ for $1 \mathrm{~min}, 50^{\circ} \mathrm{C}$ for $0.5 \mathrm{~min}$, and $70^{\circ} \mathrm{C}$ for $3 \mathrm{~min}$, with $100 \mathrm{ng}$ of total genomic DNA as the template. Fragments were amplified through two rounds of PCR, with a 1:100 dilution of the first reaction, of which $1 \mu \mathrm{l}$ was used in the second reaction to minimize carryover of the template genomic DNA in the final PCR product. Fragments were purified by ammonium acetate-isopropanol precipitation. PCR screening of $\mathrm{Cou}^{\mathrm{r}}$ B. burg-

TABLE 2. Oligonucleotide primers used in this study

\begin{tabular}{|c|c|c|c|}
\hline \multicolumn{2}{|c|}{ Primer } & \multirow{2}{*}{ Sequence $\left(5^{\prime} \rightarrow 3^{\prime}\right)$} & \multirow{2}{*}{ Gene } \\
\hline No. ${ }^{a}$ & Designation & & \\
\hline 1 & gb.18 & GCAATAATAATTGAAAGAGATT & opp $A$ \\
\hline 2 & $\mathrm{gb} .33$ & CAAATTAAATAACTAACATC & guaB \\
\hline 3 & gb. 45 & TAGATCATTGCAAACAAT & 5'-оррA \\
\hline 4 & pc. 42 & GGACTGAACTTCCTTACAGT & gиаA \\
\hline 5 & $1696 \mathrm{~F}$ & CTTCAGAGATATAAAGGGCTTGGG & $g y r B$ \\
\hline 6 & $246 \mathrm{R}$ & СТСТTCATGAATATCGGTAGG & $\operatorname{gyr} B$ \\
\hline 7 & $\mathrm{U} 178 \mathrm{~F}+B g l \mathrm{II}$ & ACCAGATCTTGTTGGTTTTAGCACTATA & $5^{\prime}-g y r B$ \\
\hline 8 & $1905 \mathrm{R}+B c l \mathrm{I}$ & ACCTTGATCATTACACATCAAGATTAATTAC & gyrB \\
\hline 9 & $24 \mathrm{R}$ & CCATATATTTTTTGATTTTTCCAT & dnaA \\
\hline 10 & IIR & AATCCTTACTGGATTCAAGAG & gyrA \\
\hline
\end{tabular}

${ }^{a}$ The relative positions and orientations of primers in chromosomal or cp 26 genes are indicated by these numbers in Fig. 3A. 

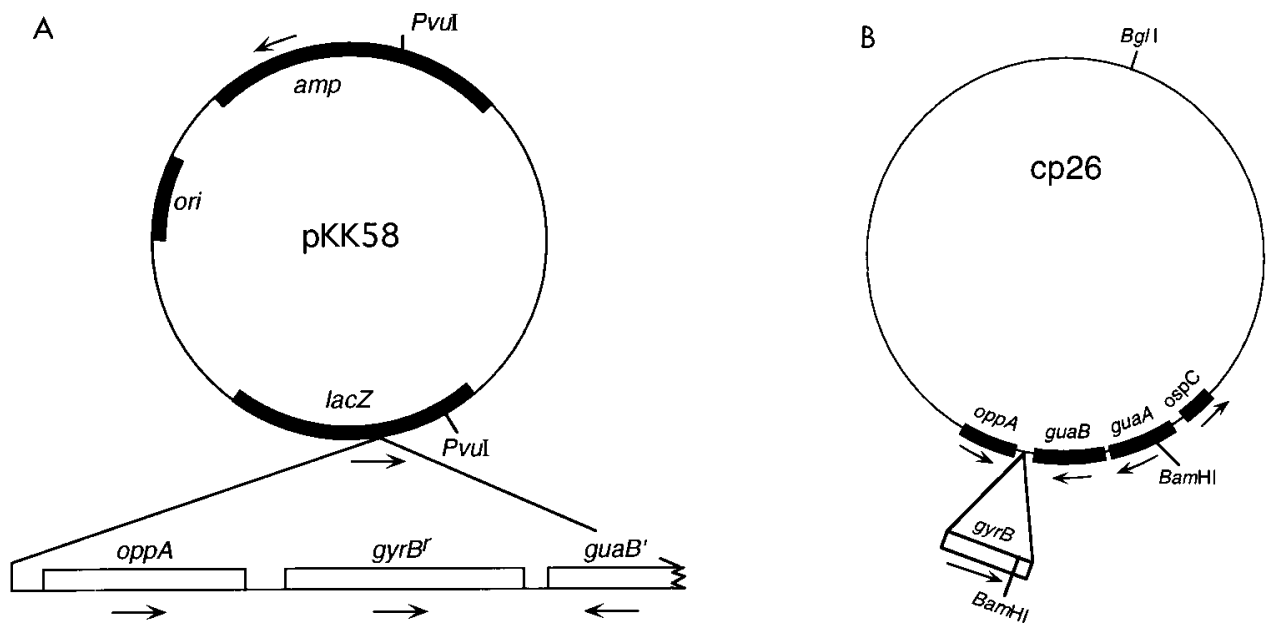

FIG. 1. pKK58 and the 26-kb circular plasmid of B. burgdorferi. (A) The positions of relevant restriction sites and genes on pKK58 and the extent of the cp26 genomic fragment with the gyr $B^{\mathrm{r}}$ insertion are as indicated. (B) The positions of relevant restriction sites and genes on cp26 and the site of the targeted gyr $B^{\mathrm{r}}$ insertion are as indicated. Arrows beneath genes point in the direction of transcription.

dorferi colonies was done in a 9600 DNA Thermal Cycler (Perkin Elmer/Applied Biosystems). Reaction volume was $20 \mu \mathrm{l}$ per sample, and PCR conditions were 30 cycles of $94^{\circ} \mathrm{C}$ for $0.5 \mathrm{~min}, 50^{\circ} \mathrm{C}$ for $0.5 \mathrm{~min}$, and $68^{\circ} \mathrm{C}$ for $2 \mathrm{~min}$. Individual B. burgdorferi colonies were picked with sterile toothpicks directly to tubes with PCR mix. There was no additional boiling or lysis step before PCR amplification. PCR products were analyzed by agarose gel electrophoresis and visualized with ethidium bromide. $\mathrm{Cou}^{\mathrm{r}}$ colonies identified by PCR as having a $\mathrm{gyr}^{\mathrm{r}}$ insertion on cp26 were subcultured in liquid medium.

Southern blots. Total genomic DNA was isolated from B. burgdorferi as previously described (37). Total plasmid DNA, including both linear and circular molecules, was isolated from B. burgdorferi with Qiagen (Chatsworth, Calif.) columns as instructed by the manufacturer. The plasmid content of Qiagen column-purified borrelial DNA is similar to that of total genomic DNA, whereas chromosomal DNA is undetectable (34a). Southern blot analyses (51) were performed with the following electrophoretic conditions: DNA was separated on a $0.8 \%$ agarose gel by field inversion electrophoresis for $24 \mathrm{~h}$ at $7 \mathrm{~V} / \mathrm{cm}$ with program 3 of a PPI-200 programmable power inverter (the forward pulse ranges between 0.15 and $4.803 \mathrm{~s}$, the reverse pulse ranges between 0.05 and $1.601 \mathrm{~s}$, and one complete cycle takes 2 min $3.9 \mathrm{~s}$ ) (MJ Research, Watertown, Mass.). DNA was transferred bidirectionally to Biotrans nylon membranes (ICN, Irvine, Calif.) and hybridized with a radiolabeled probe at $55^{\circ} \mathrm{C}$ in rotating bottles in a hybridization oven (Bellco, Vineland, N.J.) (37). Probe fragments were generated by PCR amplification, and the purified PCR products were radiolabeled with $\left[\alpha-{ }^{32}\right.$ P]dATP (Du Pont, Boston, Mass.) by random priming (Life Technologies, Gaithersburg, Md.).

\section{RESULTS}

Construction of a $\mathrm{gyrB}^{\mathrm{r}} / \mathrm{cp} 26 \mathrm{DNA}$ fragment for allelic exchange. To generate a DNA fragment for pilot gene inactivation experiments, the complete gyr $B^{\mathrm{r}}$ gene, including the promoter, of $\mathrm{Cou}^{\mathrm{r}}$ B. burgdorferi clone B31-NGR was amplified by PCR and inserted into a previously cloned fragment that spanned the opp $A$ and guaB genes from cp26. The $g y r B^{\mathrm{r}}$ gene was cloned into the intergenic region between the $3^{\prime}$ ends of the converging genes; the resulting recombinant, pKK58, has greater than $1 \mathrm{~kb}$ of cp26 sequence flanking either side of $g y r B^{\mathrm{r}}$ (Fig. 1A). A linearized version of this plasmid, in which the gene conferring ampicillin resistance was inactivated by digestion with $P v u \mathrm{I}$, was the DNA fragment used in the initial transformations. The relative positions on cp26 of opp $A$, guaB, guaA, ospC , and the targeted insertion site for $g y r B^{\mathrm{r}}$ are shown in Fig. 1B.

Screening of $\mathrm{Cou}^{\mathbf{r}}$ transformants by PCR analysis. B. burgdorferi B31 was transformed by electroporation with linearized pKK58. Sham electroporations without DNA, or in which DNA was added after electroporation, were done to control for spontaneous $\mathrm{Cou}^{\mathrm{r}}$ B. burgdorferi. Approximately 1 in $10^{5}$ bacteria were $\mathrm{Cou}^{\mathrm{r}}$ following transformation with $1 \mu \mathrm{g}$ of linearized pKK58 DNA. Spontaneous resistance arose at a frequency of about 5 in $10^{8}$ bacteria. Colonies were screened for targeted insertion on cp26 by PCR (Fig. 2), using opposing

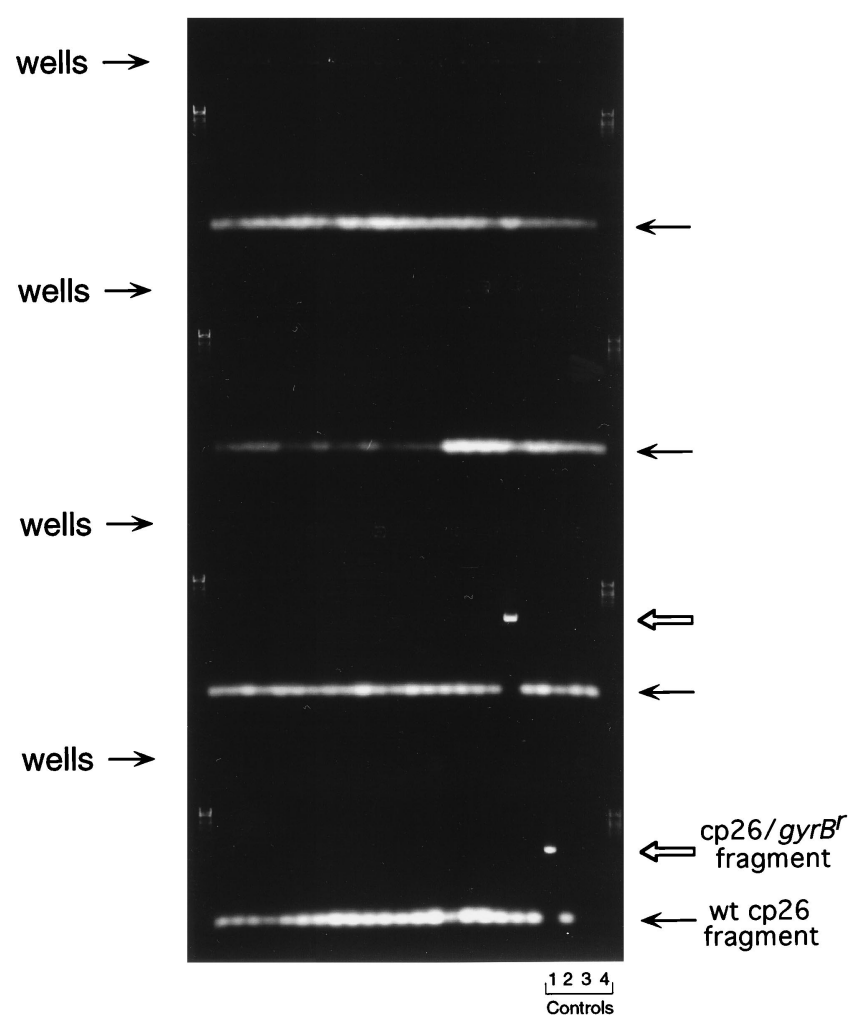

FIG. 2. Screening $\mathrm{Cou}^{\mathrm{r}}$ transformants for $g y r B^{\mathrm{r}}$ insertion on $\mathrm{cp} 26$ following electroporation with pKK58 DNA. Individual $B$. burgdorferi colonies were PCR amplified with primers 1 and 2 (Table 2 and Fig. 3A). PCR products from 96 samples were analyzed by agarose gel electrophoresis and visualized with ethidium bromide. The positions of the sample wells (four sets) are indicated on the left. The first and last samples in each row are size standards. Open and closed arrows on the right indicate the mobilities of the cp26 PCR fragment with and without the $g y r B^{\mathrm{r}}$ insertion, respectively. Control samples amplified at the same time as the colonies were pKK58 (lane 1), wt B31 (lane 2), a blank spot on the plate (lane 3 ), and the reagent blank (lane 4). 
A
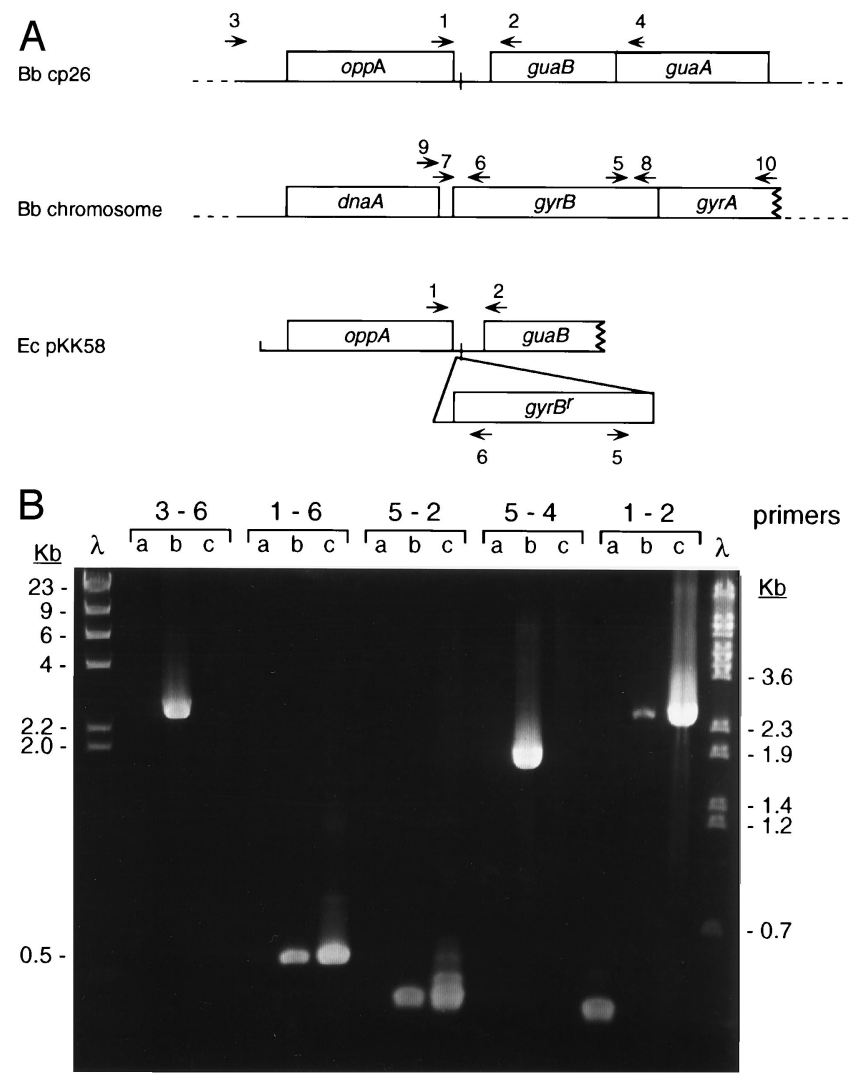

FIG. 3. Confirmation of $g y r B^{\mathrm{r}}$ insertion on $\mathrm{cp} 26$ in $\mathrm{Cou}^{\mathrm{r}}$ transformants. (A) The locations and orientations of primers on B. burgdorferi $(\mathrm{Bb}) \mathrm{cp} 26$ and chromosomal genes are as indicated. Individual primer sequences are given in Table 2. The extent of cloned cp26 DNA and the position of the gyrB ${ }^{\mathrm{r}}$ insertion in $E$. coli $(\mathrm{Ec})$ plasmid pKK58 are as shown. (B) wt B31 (lanes a), transformant B31-67 (lanes b), and pKK58 (lanes c) DNA preparations were PCR amplified with primer pairs indicated above the lanes, separated by agarose gel electrophoresis, and visualized with ethidium bromide. The mobilities of size standards are indicated at the sides.

primers in the $о p p A$ and guaB genes (primers 1 and 2 [Fig. $3 \mathrm{~A}]$ ); the primer-binding sites were also present in the pKK58 DNA fragment that was used in the transformation.

Depending on where the donor DNA fragment recombined, at least three different classes of $\mathrm{Cou}^{\mathrm{r}}$ transformants should be identifiable by PCR with these primers: (i) the desired event, homologous recombination with flanking cp26 sequences, would generate a single PCR fragment that is approximately 2 $\mathrm{kb}$ larger than the wt cp26 fragment as a result of the insertion of $g y r B^{\mathrm{r}}$; (ii) homologous recombination between $g y r B^{\mathrm{r}}$ sequences on pKK58 DNA and the chromosomal gyrB gene would leave only a wt PCR target on cp26; and (iii) illegitimate recombination at a nonhomologous site would give rise to two PCR fragments, one from the unaltered cp26 locus and a second, larger fragment from the pKK58 insertion elsewhere.

The results of one such experiment are shown in Fig. 2. Ninety-two colonies were tested by PCR; 91 colonies had a PCR fragment that was the same size as the wt fragment from untransformed spirochetes, and one colony had a PCR fragment that was consistent with the insertion of $g y r B^{\mathrm{r}}$ on cp26. No amplified products were obtained when a blank spot on the plate instead of a colony was picked (Fig. 2, lane 3, controls), indicating that neither the DNA used in the electroporation nor that of coumermycin $\mathrm{A}_{1}$-susceptible dead bacteria gave rise to the amplified fragments. In total, 2 of $461(0.4 \%)$ of the $\mathrm{Cou}^{\mathrm{r}}$ colonies screened in this experiment appeared to have $g y r B^{\mathrm{r}}$ inserted at the targeted site on cp26. The other 459 colonies had a PCR fragment identical to the wt cp26 locus; these represent transformants in which the donor DNA recombined via $g y r B$ sequences at the chromosomal locus rather than via flanking $о p p A$ and guaB sequences on cp26. There were no $\mathrm{Cou}^{\mathrm{r}}$ clones with both PCR fragments, suggesting that illegitimate recombination of the transforming DNA into a nonhomologous site in the genome is rare.

Confirmation of gyrB ${ }^{\mathrm{r}}$ insertion on cp26 by PCR and Southern blot analysis. To verify the insertion of $g y r B^{\mathrm{r}}$ on $\mathrm{cp} 26$ in candidate transformants, we used PCR primers within gyr $B$ in combination with various primers in oppA and guaB. The approximate locations of these cp 26 and $g y r B$ primers are shown in Fig. 3A. The results with five primer pairs and three template DNA preparations (wt B31, transformant clone B31-67, and plasmid pKK58) are shown in Fig. 3B. Amplification products between all gyrB and cp26 primers (primer pairs 1-6, 3-6, 5-2, and 5-4) were obtained with B31-67 DNA (lanes b). No amplified products were obtained with these primers and wt B31 DNA (lanes a). No amplification products were obtained with pKK58 plasmid DNA when distal cp26 primers outside the cloned segment were used with $g y r B$ primers (primer pairs 3-6 and 5-4 [lanes c]). These data are entirely consistent with the targeted insertion of gyrB between guaB and opp $A$ on cp26 in B31-67. Identical results were obtained with transformant B31-3 (data not shown).

We did Southern blot analyses to directly demonstrate the presence of $g y r B^{\mathrm{r}}$ on $\mathrm{cp} 26$, adjacent to guaB, in those transformants that appeared to have a targeted insertion. Previous sequence analyses had identified a BamHI site in guaA (30); mapping studies indicated that this was the only BamHI site on cp26 (9a). The B31 chromosomal gyrB locus also contains a single Bam HI site (46b). Figure 1B shows the anticipated positions of the BamHI sites and genes on cp26 relative to the gyr $B^{\mathrm{r}}$ insertion. Duplicate blots, hybridized with either a guaB or a $g y r B$ probe, were made from a field inversion gel on which were electrophoresed uncut and BamHI-digested DNA preparations from representative $\mathrm{Cou}^{\mathrm{r}}$ transformants, one in which gyrB $B^{\mathrm{r}}$ was inserted into cp26 (B31-3) and one in which $g y r B^{\mathrm{r}}$ recombined with the chromosomal gyrB gene (B31-9) (Fig. 4).

Digestion of B31-9 DNA with BamHI yielded a large (approximately $26-\mathrm{kb}$ ) fragment that hybridized with the guaB probe (Fig. 4, lane 9, cut), consistent with the presence of a single BamHI site in cp26. Insertion of $g y r B^{\mathrm{r}}$ adjacent to guaB in clone B31-3 introduced another Bam HI site and consequently yielded a much smaller (approximately $3-\mathrm{kb}$ ) fragment that hybridized with the guaB probe (lane 3, cut). Hybridization of the $g y r B$ probe to uncut $\mathrm{cp} 26$ from clone B31-3 confirmed that $g y r B^{\mathrm{r}}$ is present on the plasmid in B31-3 (lane 3, uncut) and linked with guaB on the 3-kb BamHI fragment (lane 3, cut). Circular plasmids are retarded and not well resolved, relative to linear DNA, under these field inversion electrophoresis conditions (54); therefore, uncut DNA yields multiple slowly migrating cp26 bands that hybridize to the guaB probe (lanes 3 and 9, uncut). As shown in Fig. 4, we have noted an unanticipated but consistent difference in the mobility of uncut cp26 between B31-3 and B31-9, possibly reflecting a difference in DNA supercoiling. As predicted, clones B31-3 and B31-9 each contain a chromosomal gyrB allele, and the $B a m \mathrm{HI}$ fragment from this gene was the same size (approximately $50 \mathrm{~kb}$ ) in both clones. Similar results were obtained by Southern analysis of clone B31-67 (data not shown). We conclude that $\mathrm{Cou}^{\mathrm{r}}$ transformants B31-3 and B31-67 contain gyrB 


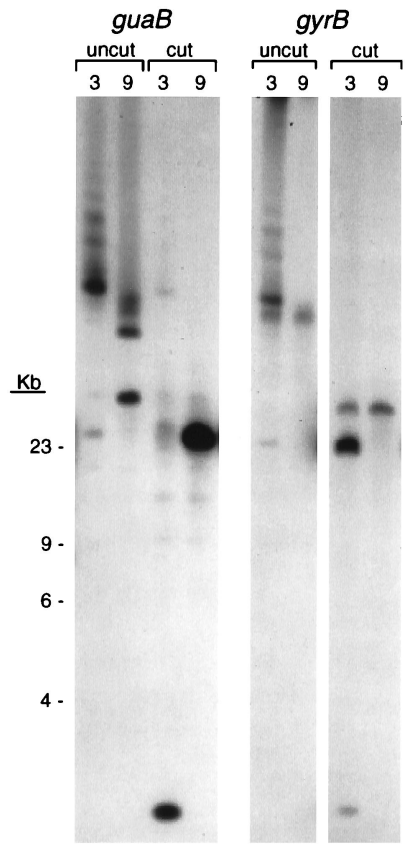

FIG. 4. Southern blot analysis of $\mathrm{Cou}^{\mathrm{r}}$ transformants. Uncut and BamHIdigested DNA preparations from transformants B31-3 (lanes 3) and B31-9 (lanes 9) were separated by field inversion gel electrophoresis, transferred to membranes, hybridized to either guaB or gyrB radiolabeled probes, and visualized by autoradiography. The source of the DNA and whether it was uncut or BamHIdigested (cut) are indicated above each lane; the probe with which each blot was hybridized is indicated at the top. The lanes showing BamHI-digested DNA hybridized with a gyrB probe are a shorter exposure of the same blot as undigested DNA. The mobilities of size standards are indicated at the left side. The gyrB probe spanned the entire gene and was the same fragment that was inserted into cp26 (amplified with primers 7 and 8 [Table 2]). The guaB probe fragment spanned nucleotides 290 to 512 of the gene (30).

at the targeted site on cp26 in addition to the $g y r B$ gene at the wt chromosomal locus. There was no evidence for insertion of gyr $B^{\mathrm{r}}$ at any other site in these bacteria or for any chromosomal or plasmid rearrangement.

Analysis of chromosomal and cp26 gyrB alleles. Although we anticipated that the DNA introduced by electroporation could generate $\mathrm{Cou}^{\mathrm{r}} B$. burgdorferi by recombination with homologous sequences on either cp26 or the chromosome, most (459 of 461) of the transformants resulted from recombination with the chromosomal $g y r B$ gene. One possible explanation for this finding is that the $g y r B^{\mathrm{r}}$ allele on $\mathrm{cp} 26$ does not confer $\mathrm{Cou}^{\mathrm{r}}$, and those rare transformants with $\mathrm{gyr}^{\mathrm{r}}$ inserted on the plasmid must also have a $\operatorname{gyr} B$ allele conferring $\mathrm{Cou}^{\mathrm{r}}$ at the chromosomal locus. Another possibility is that the normal gyrB promoter is not efficiently transcribed on cp26, perhaps because of differences in DNA supercoiling or topology between the linear chromosome and a circular plasmid, and the plasmid gyr $B^{\mathrm{r}}$ gene must acquire some additional mutation for adequate expression at this site. To address these possibilities, the gyrB genes from both loci of transformant B31-3 were amplified with primers in flanking sequences and the PCR fragments were subjected to partial sequence analysis. These studies indicated that the promoter region and residues critical for $\mathrm{Cou}^{\mathrm{r}}$ of the cp26 gyrB ${ }^{\mathrm{r}}$ allele of B31-3 were identical in sequence to the B31-NGR gyrB ${ }^{\mathrm{r}}$ DNA with which it was transformed and that the chromosomal gyrB allele of B31-3 was wt at those residues that are mutated in B31-NGR or other $\mathrm{Cou}^{\mathrm{r}}$ B. burgdorferi strains (not shown).

To directly test the ability of the cp26 gyrB allele of B31-3 to confer $\mathrm{Cou}^{\mathrm{r}}$, the PCR fragments described above were used to transform B. burgdorferi by electroporation and the number of $\mathrm{Cou}^{\mathrm{r}}$ transformants was determined by plating (Table 3 ). The chromosomal gyrB ${ }^{\mathrm{r}}$ genes from B31-NGR and B31-9 were amplified as positive controls, and the unaltered $\mathrm{cp} 26$ site from B31-9 (in which there was no $g y r B^{\mathrm{r}}$ insertion) was amplified as a negative control. The transformation frequency following electroporation of DNA from the cp26 gyrB ${ }^{\mathrm{r}}$ allele of B31-3 $\left(10^{-5}\right)$ was comparable to the transformation frequencies with DNA from the chromosomal gyrB ${ }^{\mathrm{r}}$ genes of B31-9 $\left(3 \times 10^{-6}\right)$ and B31-NGR $\left(6 \times 10^{-6}\right)$. The transformation frequency following electroporation of DNA from the chromosomal gyrB allele of B31-3 was the same as the background level of spontaneous $\operatorname{Cou}^{\mathrm{r}}\left(9 \times 10^{-8}\right)$, approximately 100 -fold less than that of the cp26 gyrB ${ }^{\mathrm{r}}$ allele. We conclude that the $g y r B^{\mathrm{r}}$ insertions on cp26 confer $\mathrm{Cou}^{\mathrm{r}}$, that no additional mutations were necessary for adequate gene expression at this site, and that some other factor dictated the low frequency of integration at this site.

The transformations described in Table 3 were done with a cp26 gyrB ${ }^{\mathrm{r}}$ fragment that contained very little cp26 flanking sequence (166 nucleotides $5^{\prime}$ and 244 nucleotides $\left.3^{\prime}\right)$. We repeated this experiment with more distal cp26 primers, located approximately $1 \mathrm{~kb}$ away on either side of the $g y r B^{\mathrm{r}}$ insertion, to amplify cp26 fragments from B31-3 and B31-9. In this experiment, the transformation frequency was $2 \times 10^{-5}$ / $\mu \mathrm{g}$ of the B31-3 cp26 gyrB $B^{\mathrm{r}}$ fragment, compared with a spontaneous $\mathrm{Cou}^{\mathrm{r}}$ frequency of less than $10^{-7}$ (B31-9 cp26 fragment, lacking gyrB ${ }^{\mathrm{r}}$ ). PCR screening of $89 \mathrm{Cou}^{\mathrm{r}}$ transformants obtained with the B31-3 cp26 gyrB ${ }^{\mathrm{r}}$ fragment indicated that all had recombined into the chromosomal gyr $B$ locus. Therefore, even when $g y r B^{\mathrm{r}}$ was derived from $\mathrm{cp} 26$, it still preferentially recombined into the chromosomal locus. This result again indicated that the low frequency of $g y r B^{\mathrm{r}}$ insertion on cp26 following transformation with pKK58 DNA was not due to the need to acquire additional mutations that allow a dominant phenotype and adequate expression of $g y r B^{\mathrm{r}}$ on $\mathrm{cp} 26$.

Transformation of $B$. burgdorferi with borrelial plasmid DNA. We wished to determine if $\mathrm{cp} 26$ containing gyrB ${ }^{\mathrm{r}}$ could be used to transform wt spirochetes to a resistant phenotype,

TABLE 3. Transformation with PCR fragments amplified from the chromosomal or cp26 gyrB alleles

\begin{tabular}{lllll}
\hline \multirow{2}{*}{ DNA $^{a}$} & \multicolumn{1}{c}{ gyrB locus $^{b}$} & \multicolumn{2}{c}{$\begin{array}{c}\text { No. of Cou } \\
\text { colonies }^{c}\end{array}$} & $\begin{array}{c}\text { Transformation } \\
\text { frequency }\end{array}$ \\
\cline { 3 - 4 } & & $0.01 \mathrm{ml}$ & $0.1 \mathrm{ml}$ & \\
\hline B31-3 & Chromosome & 0,0 & 0,2 & $9.0 \times 10^{-8}$ \\
B31-3 & cp26 & 14,13 & 106,95 & $1.0 \times 10^{-5}$ \\
B31-9 & Chromosome & 1,3 & 40,22 & $3.0 \times 10^{-6}$ \\
B31-9 & cp26 $^{e}$ & 0,0 & 0,2 & $9.0 \times 10^{-8}$ \\
B31-NGR & Chromosome & 9,3 & 68,59 & $6.3 \times 10^{-6}$ \\
\hline
\end{tabular}

${ }^{a}$ The source of genomic DNA used in the PCR to generate a fragment for transformation.

${ }^{b}$ Locus from which the gyrB allele was amplified. Primers for the chromosomal locus were 9 and 10, and primers for cp26 were 1 and 2 (Fig. 3A and Table 2).

${ }^{c}$ The final volume of each transformation was $10 \mathrm{ml}$. Of this, 0.01 and $0.1 \mathrm{ml}$ were plated in duplicate from a single transformation, and the number of $\mathrm{Cou}^{\mathrm{r}}$ colonies per plate is given.

${ }^{d}$ Fraction of viable bacteria in the transformation that are $\mathrm{Cou}^{\mathrm{r}}$ per microgram of donor DNA. All transformations were done with $1 \mu \mathrm{g}$ of DNA and contained approximately $10^{9}$ viable bacteria at the time of plating. This figure was calculated by multiplying the total number of $\mathrm{Cou}^{\mathrm{r}}$ colonies obtained per volume plated $(0.22 \mathrm{ml})$ by the appropriate factor $(45.5)$ to account for the total volume $(10 \mathrm{ml})$ of the transformation mix and dividing by $10^{9}$.

${ }^{e}$ B31-9 does not contain $g y r B^{\mathrm{r}}$ on cp26. The PCR fragment obtained with primers 1 and 2 from B31-9 was used as a control for spontaneous Cour ${ }^{\mathrm{r}}$. 
TABLE 4. Transformation with borrelial plasmid DNA

\begin{tabular}{|c|c|c|c|c|c|c|}
\hline \multirow{2}{*}{ Expt } & \multirow{2}{*}{$\begin{array}{l}\text { Plasmid } \\
\text { DNA }^{a}\end{array}$} & \multicolumn{3}{|c|}{ No. of $\mathrm{Cou}^{\mathrm{r}}$ colonies $^{b}$} & \multirow{2}{*}{$\begin{array}{c}g y r B^{\mathrm{r}} \text { on } \\
\mathrm{cp} 26^{c}\end{array}$} & \multirow{2}{*}{$\begin{array}{l}\text { Transformatio } \\
\text { frequency }^{d}\end{array}$} \\
\hline & & $0.1 \mathrm{ml}$ & $0.5 \mathrm{ml}$ & $1.0 \mathrm{ml}$ & & \\
\hline \multirow[t]{3}{*}{ I } & B31-3 & 3 & 11 & 17 & $1 / 31$ & $1.9 \times 10^{-7}$ \\
\hline & B31-67 & 1 & 8 & 10 & $2 / 19$ & $1.2 \times 10^{-7}$ \\
\hline & B31-9 & 0 & $\mathrm{ND}^{e}$ & 9 & ND & $5.6 \times 10^{-8}$ \\
\hline \multirow[t]{3}{*}{ II } & B31-67, uncut & & $5,4,5,6$ & & $1 / 20$ & $1.0 \times 10^{-7}$ \\
\hline & $\begin{array}{l}\text { B31-67, cut } \\
\text { with } B g l I^{f}\end{array}$ & & $27,37,27$ & & $16 / 80$ & $6.0 \times 10^{-7}$ \\
\hline & No DNA & & $5,2,7,5$ & & ND & $1.0 \times 10^{-7}$ \\
\hline
\end{tabular}

${ }^{a}$ Plasmid DNA isolated from B. burgdorferi by using Qiagen columns included all linear and circular plasmids. B31-9 cp26 does not contain gyrB ${ }^{\mathrm{r}}$ and thus represents a control for spontaneous $\mathrm{Cou}^{\mathrm{r}}$

${ }^{b}$ The final volume of each electroporation was $10 \mathrm{ml}$. Of this, the indicated volume was plated, and the number of $\mathrm{Cou}^{\mathrm{r}}$ colonies per plate is given.

${ }^{c}$ Colonies were screened for $\operatorname{gyr} B^{\mathrm{r}}$ insertion on $\mathrm{cp} 26$ by PCR with primers 1 and 2, as indicated in Fig. 3A. The fraction given represents the number of colonies positive for $g y r B^{\mathrm{r}}$ on $\mathrm{cp} 26$ per total number of colonies screened.

${ }^{d}$ Fraction of viable bacteria in the transformation that are $\mathrm{Cou}^{\mathrm{r}}$ per microgram of donor DNA.

${ }^{e} \mathrm{ND}$, not done.

${ }^{f}$ Plasmid DNA from B31-67 was digested with $B g l$ I before electroporation. Not all $\mathrm{Cou}^{\mathrm{r}}$ colonies were screened by PCR.

either by displacing the resident $\mathrm{cp} 26$ or by recombining with it. Transformation with borrelial plasmid DNA would differ from previous experiments in several ways that could potentially influence the uptake, degradation, and recombination of donor DNA. First, cp26, as a supercoiled circular plasmid, represents a different physical form of DNA than linear pKK58 or PCR fragments. Second, native cp 26 would contain borrelial DNA modifications that would not be present on Escherichia coli DNA or PCR fragments. Finally, there is much more cp 26 sequence flanking gyrB ${ }^{\mathrm{r}}$ on the intact plasmid than there was on pKK58.

When total plasmid DNA preparations from $\mathrm{Cou}^{\mathrm{r}}$ transformants B31-3 and B31-67 were transformed by electroporation back into wt $B$. burgdorferi, the frequencies of $\mathrm{Cou}^{\mathrm{r}}$ colonies following transformation $\left(1.9 \times 10^{-7}\right.$ and $1.3 \times 10^{-7}$, respectively) were only slightly greater than that of spontaneous resistance in the negative control $\left(5.6 \times 10^{-8}\right.$; B31-9) (Table 4, experiment I). This reduction in transformation frequency, relative to the original experiments, could be explained largely by the difference in complexity between total plasmid DNA and the PCR fragments (approximately $2.5 \times 10^{5}$ and $5 \times 10^{3}$ $\mathrm{bp}$, respectively) and the corresponding molarity of $g y r B^{\mathrm{r}}$ sequences present in $1 \mu \mathrm{g}$ of DNA used in the transformations. All the same, PCR screening indicated that 3 of $50 \mathrm{Cou}^{\mathrm{r}}$ colonies following transformation with B31-3 and B31-67 plasmid DNA had gyrB ${ }^{\mathrm{r}}$ on cp26 (Table 4, experiment I). Sequence analysis of the chromosomal gyr $B$ locus from $10 \mathrm{Cou}^{\mathrm{r}}$ colonies from this transformation that did not have a $g y r B$ insertion on cp26 indicated that 5 were transformants and 5 were spontaneous $\mathrm{Cou}^{\mathrm{r}}$ mutants. Since approximately half of the $\mathrm{Cou}^{\mathrm{r}}$ colonies with B31-3 plasmid DNA were spontaneous mutants, $g y r B^{\mathrm{r}}$ insertion on cp 26 probably occurred in more than $10 \%$ of the actual transformants in this experiment. We conclude that the overall transformation efficiency was not increased with borrelial plasmid DNA relative to linear PCR fragments or $E$. coli plasmid fragments, but that a larger fraction of the transformants had $g y r B^{\mathrm{r}}$ at the targeted site on cp26.

In the previous experiment, transformants carrying gyr $B^{\mathrm{r}}$ on cp 26 could have arisen by recombination between donor and resident plasmids or by displacement of resident $\mathrm{cp} 26$ by donor plasmid. We reasoned that linearizing cp26 in the donor DNA should reduce the number of transformants with $g y r B^{\mathrm{r}}$ on cp26 if the donor plasmid was displacing the resident plasmid, because a second event, religation, would be necessary to stably maintain the transforming plasmid DNA. Conversely, if transformants containing $g y r B^{\mathrm{r}}$ on $\mathrm{cp} 26$ arose by recombination between donor and resident plasmids, linearizing cp26 might stimulate this event because a discontinuity would already exist in the transforming DNA. We subsequently compared transformation efficiencies of uncut and linearized total plasmid DNA from B31-67. Mapping studies of cp26 have demonstrated a single $B g l \mathrm{I}$ site, approximately $13 \mathrm{~kb}$ away in both directions from the gyr $B^{\mathrm{r}}$ insertion site (Fig. 1B) (9a). Transformation with $B g l$ I-digested plasmid DNA resulted in approximately sixfold more $\mathrm{Cou}^{\mathrm{r}}$ colonies than with uncut plasmid per microgram of DNA $\left(6 \times 10^{-7}\right.$, and $1 \times 10^{-7}$, respectively $)$ (Table 4, experiment II). Again, the frequency of $\mathrm{Cou}^{\mathrm{r}}$ transformants following electroporation with uncut plasmid DNA was not different from that of spontaneous $\mathrm{Cou}^{\mathrm{r}}$ colonies in the sham electroporation without DNA $\left(10^{-7}\right)$. PCR screening of the transformants demonstrated the presence of $g y r B^{\mathrm{r}}$ on cp26 in 16 of $80(20 \%)$ of the $\mathrm{Cou}^{\mathrm{r}}$ colonies following electroporation with $B g l \mathrm{I}$-digested plasmid DNA (Table 4, experiment II). Since the overall frequency of transformation was increased with linearized cp26 and the fraction of transformants with $g y r B^{\mathrm{r}}$ on $\mathrm{cp} 26$ did not decrease, this experiment suggests that recombination between donor DNA and resident cp26, rather than displacement of the wt plasmid, probably generated the $\mathrm{Cou}^{\mathrm{r}}$ transformants carrying gyrB ${ }^{\mathrm{r}}$ on cp26 in these experiments with borrelial plasmid DNA.

\section{DISCUSSION}

We have carried out important steps toward the goal of gene inactivation by allelic exchange in B. burgdorferi, using as a selectable marker a mutated borrelial $g y r B$ gene that confers $\mathrm{Cou}^{\mathrm{r}}$. For this strategy to work, $g y r B^{\mathrm{r}}$ must confer a dominant phenotype because the wt (coumermycin $\mathrm{A}_{1}$-susceptible) gyr $B$ gene will still be present on the chromosome. Although gyr $B^{\mathrm{r}}$ is a dominant mutation in other bacteria (31), our initial transformation results were not entirely convincing that this was true in B. burgdorferi: only $0.4 \%$ of the $\mathrm{Cou}^{\mathrm{r}}$ colonies following electroporation with linearized pKK58 DNA were generated by targeted insertion of $g y r B^{\mathrm{r}}$ on $\mathrm{cp} 26$. However, the frequency of $g y r B^{\mathrm{r}}$ insertion on cp26 $\left(4 \times 10^{-8}\right)$ was still much greater than what would be anticipated for two independent events, in which transforming DNA recombined at both chromosomal and cp26 sites $\left(10^{-10}\right)$. Subsequent experiments demonstrated that $\mathrm{Cou}^{\mathrm{r}}$ borreliae with the gyrB $B^{\mathrm{r}}$ allele inserted on cp26 were heterozygous for the gyr $B$ alleles, with a wt copy of the gene on the chromosome (Table 3 ). Therefore, $g y r B^{\mathrm{r}}$ is dominant and can be used as a selectable marker for gene inactivation in B. burgdorferi. We conclude, however, that some aspect of the transformation with pKK58 DNA favored recombination at the chromosomal gyrB locus rather than via cp26 sequences. A strong possibility is that the amount of cp26 flanking sequence in pKK58 $\left(1.75 \mathrm{~kb} \mathrm{5}^{\prime}\right.$ and $1.4 \mathrm{~kb} \mathrm{3'}$ of gyr $\left.{ }^{\mathrm{r}}\right)$ was insufficient to efficiently mediate homologous recombination on either side of a 2-kb segment of heterologous DNA $\left(\right.$ gyrB $\left.B^{\mathrm{r}}\right)$. There is precedent in other transformation systems for preferential incorporation of small mismatches rather than large regions of heterologous sequences (33). It is also possible that the biochemistry of homologous recombination with the linear donor DNA is different if the substrate is a supercoiled plasmid rather than the linear chromosome. In E. coli, homologous recombination with plasmids can be mediated by a RecAindependent pathway (23). In addition, targeted insertion of 
gyr $B^{\mathrm{r}}$ into cp26 requires a double crossover, whereas recombination into $g y r B$ on the chromosome could occur by gene conversion (requiring only homologous pairing spanning the mutation and mismatch repair), which might be more frequent.

When uncut, total borrelial plasmid DNA from a Cour transformant with $g y r B^{\mathrm{r}}$ inserted on $\mathrm{cp} 26$ was transformed back into coumermycin $\mathrm{A}_{1}$-susceptible borreliae, the transformation frequency per microgram of DNA was comparable to the level of spontaneous $\mathrm{Cou}^{\mathrm{r}}$ (Table 4, experiment I). Transformation with total borrelial plasmid DNA that had been digested with $B g l$ I, which linearizes cp26, increased the transformation frequency about sixfold over the uncut plasmid level (Table 4, experiment II); approximately $20 \%$ of these $\mathrm{Cou}^{\mathrm{r}}$ colonies carried cp26 with $g y r B^{\mathrm{r}}$. These experiments indicate that $\mathrm{Cou}^{\mathrm{r}}$ transformants with $\operatorname{gyr} B$ on $\mathrm{cp} 26$ are generated at a 50 -foldhigher frequency with linearized cp26 plasmid DNA than with the smaller linear pKK58 DNA fragments used in the initial transformation experiments $(20 \%$ versus $0.4 \%)$. This finding is consistent with the interpretation that increasing the amount of cp26 flanking sequence on either side of $g y r B$ (approximately $13 \mathrm{~kb}$ versus $1.5 \mathrm{~kb}$ ) facilitated homologous recombination with cp26. Additional experiments are necessary to determine what stimulates recombination at the targeted site relative to the chromosomal gyrB locus. A different selectable marker that did not have a wt borrelial counterpart would obviously circumvent this problem. We are currently investigating the utility of a gene conferring chloramphenicol resistance (18), which has been used for gene inactivation by allelic exchange in the spirochete Serpulina hyodysenteriae (38). We are also simplifying our screen for targeted insertion of $g y r B^{\mathrm{r}}$ by incorporating a gene encoding a fluorescent marker between $g y r B^{\mathrm{r}}$ and flanking sequences.

In the previous experiments with uncut borrelial plasmid DNA, $\mathrm{Cou}^{\mathrm{r}}$ colonies containing $\mathrm{gyrB}^{\mathrm{r}}$ on the plasmid could have arisen either from stable maintenance of cp26 DNA that was introduced by electroporation, following segregation of wt cp26, or from recombination between the transforming DNA and the resident $\mathrm{cp} 26$. We cannot determine which occurred because $g y r B^{\mathrm{r}}$ is the only marker that distinguishes the transforming and the resident forms of cp26. It is not known if borreliae exhibit plasmid incompatibility such that stable maintenance of a plasmid introduced by transformation would be inhibited by a homologous resident plasmid. These experiments point out one difficulty in attempting transformation with cp26 and investigating its potential utility as a borrelial plasmid vector: all $B$. burgdorferi isolates analyzed contain cp26 $(26,28,53)$. However, cp26 containing $g y r B$ as a selectable marker might be used to transform other members of the genus, such as $B$. hermsii. Although $B$. hermsii contains a number of circular plasmids, it does not appear to have one that is closely related to cp26; guaA, guaB, opp $A$, and $\operatorname{sp} C$ homologs are present on linear plasmids or the chromosome in $B$. hermsii $(9,29,30)(34 a)$. Conversely, a good approach to developing a plasmid vector for $B$. burgdorferi may be to introduce a selectable marker such as gyr $B^{\mathrm{r}}$ into a $B$. hermsii plasmid. Alternatively, we have identified a family of related $32-\mathrm{kb}$ circular plasmids in $B$. burgdorferi that can coexist within the same spirochete but are not present in all infectious clones (54). One of these plasmids may represent a more useful plasmid vector for B. burgdorferi.

A potential problem in inactivating borrelial genes, either chromosomal or plasmid borne, is the inherent polyploidy of the genome: Kitten and Barbour have demonstrated that both the chromosome and the plasmids of $B$. hermsii are present at 8 to 16 copies per spirochete (21). Theoretically, heterozygotes should be generated by transformation in which the selectable marker had interrupted only some copies of the gene. However, we never found any examples of heterozygosity (with reference to cp26) following transformation with pKK58 or borrelial plasmid DNA. Therefore, the mechanisms of plasmid replication and segregation in borreliae must ensure homozygosity by the time a single spirochete has replicated to form a detectable colony. In vivo, $B$. hermsii must deal with this same problem in order to derive a clonal advantage from Vmp antigenic variation $(3,21)$, whereby the expressed $v m p$ gene, present on a multicopy plasmid, is replaced with a copy of a previously silent $v m p$ gene. $B$. hermsii must either suppress expression from some copies of this plasmid or coexpress Vmps from switched and unswitched plasmids until plasmid homozygosity is attained by segregation.

In this report, we demonstrated targeted insertion of an antibiotic resistance marker into a circular plasmid of $B$. burgdorferi via homologous recombination with flanking sequences. This is the first example in borreliae of a nonspontaneous mutation whereby the altered or inactivated targeted sequence does not by itself confer an intrinsic selectable advantage. Previously, $B$. burgdorferi variants have been selected by treatment with specific antisera that permitted only growth of escape mutants lacking particular outer surface proteins $(13,14$, $41,42,43,44)$. Similarly, gyrB mutants were selected by the ability to grow in the presence of coumermycin $A_{1}(47,48)$. Such direct approaches to isolating specific mutations are powerful but restricted to a limited number of genes. The study presented in this report is an important step toward developing a convenient means of allelic exchange in B. burgdorferi with which to inactivate most genes. We are currently using gyr $B^{\mathrm{r}}$ to inactivate genes of interest on cp26 in order to study their roles in the infectious cycle of $B$. burgdorferi between ticks and mammals.

\section{ACKNOWLEDGMENTS}

We thank T. G. Schwan, J. Hinnebusch, R. Belland, and S. Hill for critical review of the manuscript, S. Smaus for assistance in manuscript preparation, and G. Hettrick and R. Evans for artwork and photography. We thank Van Tamplin, Joan Strange, and Holly Vestal for assistance with gyrB DNA sequencing.

This work was supported in part by funds provided by the Office of Research Administration at the University of Montana (D.S.S.)

\section{REFERENCES}

1. Barbour, A. G. 1984. Isolation and cultivation of Lyme disease spirochetes. Yale J. Biol. Med. 57:521-525.

2. Barbour, A. G. 1988. Plasmid analysis of Borrelia burgdorferi, the Lyme disease agent. J. Clin. Microbiol. 26:475-478.

3. Barbour, A. G. 1990. Antigenic variation of a relapsing fever Borrelia species Annu. Rev. Microbiol. 44:155-171.

4. Barbour, A. G. 1993. Linear DNA of Borrelia species and antigenic variation. Trends Microbiol. 1:236-239.

5. Barbour, A. G., and C. F. Garon. 1987. Linear plasmids of the bacterium Borrelia burgdorferi have covalently closed ends. Science 237:409-411.

6. Baril, C., C. Richaud, G. Baranton, and I. Saint Girons. 1989. Linear chromosome of Borrelia burgdorferi. Res. Microbiol. 140:507-516.

7. Bergstrom, S., C. F. Garon, A. G. Barbour, and J. MacDougall. 1992. Extrachromosomal elements of spirochetes. Res. Microbiol. 143:623-628.

8. Burgdorfer, W., A. G. Barbour, S. F. Hayes, J. L. Benach, E. Grunwaldt, and J. P. Davis. 1982. Lyme disease-a tick-borne spirochetosis? Science 216: 1317-1319.

9. Carter, C. J., S. Bergstrom, S. J. Norris, and A. G. Barbour. 1994. A family of surface-exposed proteins of 30 kilodaltons in the genus Borrelia. Infect. Immun. 62:2792-2799.

9a.Casjens, S. Unpublished data.

10. Casjens, S., M. DeLange, H. L. Ley, III, P. Rosa, and W. M. Huang. 1995. Linear chromosomes of Lyme disease agent spirochetes: genetic diversity and conservation of gene order. J. Bacteriol. 177:2769-2780.

11. Casjens, S., and W. M. Huang. 1993. Linear chromosomal physical an genetic map of Borrelia burgdorferi, the Lyme disease agent. Mol. Microbiol. 8:967-980. 
12. Casjens, S., and W. M. Huang. 1996. The linear chromosomes of Borrelia burgdorferi and the other Lyme disease spirochetes. In F. de Bruijn, G. Weinstock, and J. Lupski (ed.), Bacterial genomes: physical structure and analysis, in press. Chapman and Hall, New York.

13. Cinco, M. 1992. Selection of a Borrelia burgdorferi antigenic variant by cultivation in the presence of increasing amounts of homologous immune serum. FEMS Microbiol. Lett. 92:15-18.

14. Coleman, J. L., R. C. Rogers, P. A. Rosa, and J. L. Benach. 1994. Variations in the $\operatorname{sp} B$ gene of Borrelia burgdorferi result in differences in monoclonal antibody reactivity and in production of escape variants. Infect. Immun. 62:303-307.

15. Davidson, B. E., J. MacDougall, and I. Saint Girons. 1992. Physical map of the linear chromosome of the bacterium Borrelia burgdorferi 212, a causative agent of Lyme disease, and localization of rRNA genes. J. Bacteriol. 174: 3766-3774.

16. Ferdows, M. S., and A. G. Barbour. 1989. Megabase-sized linear DNA in the bacterium Borrelia burgdorferi, the Lyme disease agent. Proc. Natl. Acad. Sci. USA 86:5969-5973.

17. Hinnebusch, J., and K. Tilly. 1993. Linear plasmids and chromosomes in bacteria. Mol. Microbiol. 10:917-922.

17a.Hogan, D., and P. Rosa. Unpublished data

18. Horinouchi, S., and B. Weisblum. 1982. Nucleotide sequence and functional map of pC194, a plasmid that specifies inducible chloramphenicol resistance. J. Bacteriol. 150:815-825.

19. Hyde, F. W., and R. C. Johnson. 1988. Characterization of a circular plasmid from Borrelia burgdorferi, etiologic agent of Lyme disease. J. Clin. Microbiol. 26:2203-2205.

20. Johnson, R. C., G. P. Schmid, F. W. Hyde, A. G. Steigerwalt, and D. J. Brenner. 1984. Borrelia burgdorferi sp. nov.: etiologic agent of Lyme disease. Int. J. Syst. Bacteriol. 34:496-497.

21. Kitten, T., and A. G. Barbour. 1992. The relapsing fever agent Borrelia hermsii has multiple copies of its chromosome and linear plasmids. Genetics 132:311-324.

22. Koide, A., and J. A. Hoch. 1994. Identification of a second oligopeptide transport system in Bacillus subtilis and determination of its role in sporulation. Mol. Microbiol. 13:417-426.

23. Kowalczykowski, S. C., D. A. Dixon, A. K. Eggleston, S. D. Lauder, and W. M. Rehrauer. 1994. Biochemistry of homologous recombination in Escherichia coli. Microbiol. Rev. 58:401-465.

24. Kurtti, T. J., U. G. Munderloh, R. C. Johnson, and G. G. Ahlstrand. 1987. Colony formation and morphology in Borrelia burgdorferi. J. Clin. Microbiol. 25:2054-2058.

25. Lane, R. S., J. Piesman, and W. Burgdorfer. 1991. Lyme borreliosis: relation of its causative agent to its vectors and hosts in North America and Europe. Annu. Rev. Entomol. 36:587-609.

26. Livey, I., C. P. Gibbs, R. Schuster, and F. Dorner. 1995. Evidence for lateral transfer and recombination in OspC variation in Lyme disease Borrelia. Mol. Microbiol. 18:257-269.

27. Magnuson, R., J. Solomon, and A. D. Grossman. 1994. Biochemical and genetic characterization of a competence pheromone from B. subtilis. Cell 77:207-216

28. Marconi, R. T., D. S. Samuels, and C. F. Garon. 1993. Transcriptional analyses and mapping of the $\operatorname{sp} \mathrm{C}$ gene in Lyme disease spirochetes. J. Bacteriol. 175:926-932

29. Margolis, N., D. Hogan, W. Cieplak, Jr., T. G. Schwan, and P. A. Rosa. 1994. Homology between Borrelia burgdorferi OspC and members of the family of Borrelia hermsii variable major proteins. Gene 143:105-110.

30. Margolis, N., D. Hogan, K. Tilly, and P. A. Rosa. 1994. Plasmid location of Borrelia purine biosynthesis gene homologs. J. Bacteriol. 176:6427-6432.

31. Maxwell, A. 1993. The interaction between coumarin drugs and DNA gyrase. Mol. Microbiol. 9:681-686.

32. Mullis, K., F. Faloona, S. Scharf, R. Saiki, G. Horn, and H. Erlich. 1986. Specific enzymatic amplification of DNA in vitro: the polymerase chain reaction. Cold Spring Harbor Symp. Quant. Biol. 51:263-273.

33. Pasta, F., and M. A. Sicard. 1996. Exclusion of long heterologous insertions and deletions from the pairing synapsis in pneumococcal transformation. Microbiology 142:695-705.

34. Perego, M., C. F. Higgins, S. R. Pearce, M. P. Gallagher, and J. A. Hoch. 1991. The oligopeptide transport system of Bacillus subtilis plays a role in the initiation of sporulation. Mol. Microbiol. 5:173-185.

34a.Rosa, P. Unpublished data.

35. Rosa, P. A., and D. Hogan. 1992. Colony formation by Borrelia burgdorferi in solid medium: clonal analysis of osp locus variants, p. 95-103. In U. G. Munderloh and T. J. Kurtti (ed.), First International Conference on Tick Borne Pathogens at the Host-Vector Interface: an agenda for research. University of Minnesota, St. Paul, Minn.

36. Rosa, P. A., T. Schwan, and D. Hogan. 1992. Recombination between genes encoding major outer surface proteins A and B of Borrelia burgdorferi. Mol. Microbiol. 6:3031-3040.

37. Rosa, P. A., and T. G. Schwan. 1989. A specific and sensitive assay for the Lyme disease spirochete Borrelia burgdorferi using the polymerase chain reaction. J. Infect. Dis. 160:1018-1029.

38. Rosey, E. L., M. J. Kennedy, D. K. Petrella, R. G. Ulrich, and R. J. Yancey, Jr. 1995. Inactivation of Serpulina hyodysenteriae flaA1 and flaB1 periplasmic flagellar genes by electroporation-mediated allelic exchange. J. Bacteriol. 177:5959-5970.

39. Rudner, D. Z., J. R. LeDeaux, K. Ireton, and A. D. Grossman. 1991. The spoOK locus of Bacillus subtilis is homologous to the oligopeptide permease locus and is required for sporulation and competence. J. Bacteriol. 173:13881398.

40. Ruhfel, R. E., D. A. Manias, and G. M. Dunny. 1993. Cloning and characterization of a region of the Enterococcus faecalis conjugative plasmid, pCF10, encoding a sex pheromone-binding function. J. Bacteriol. 175:52535259 .

41. Sadziene, A., A. G. Barbour, P. A. Rosa, and D. D. Thomas. 1993. An OspB mutant of Borrelia burgdorferi has reduced invasiveness in vitro and reduced infectivity in vivo. Infect. Immun. 61:3590-3596.

42. Sadziene, A., P. A. Rosa, P. A. Thompson, D. M. Hogan, and A. G. Barbour 1992. Antibody-resistant mutants of Borrelia burgdorferi: in vitro selection and characterization. J. Exp. Med. 176:799-809.

43. Sadziene, A., P. A. Thompson, and A. G. Barbour. 1993. In vitro inhibition of Borrelia burgdorferi growth by antibodies. J. Infect. Dis. 167:165-172.

44. Sadziene, A., B. Wilske, M. S. Ferdows, and A. G. Barbour. 1993. The cryptic ospC gene of Borrelia burgdorferi B31 is located on a circular plasmid. Infect. Immun. 61:2192-2195.

45. Saiki, R. K., S. Scharf, F. Faloona, K. B. Mullis, G. T. Horn, H. A. Erlich, and N. Arnheim. 1985. Enzymatic amplification of beta-globin genomic sequences and restriction site analysis for diagnosis of sickle cell anemia. Science 230:1350-1354.

45a.Saint Girons, I., I. G. Old, and B. E. Davidson. 1994. Molecular biology of the Borrelia, bacteria with linear replicons. Microbiology 140:1803-1816.

46. Samuels, D. S. 1995 . Electrotransformation of the spirochete Borrelia burgdorferi, p. 253-259. In J. A. Nickoloff (ed.), Methods in molecular biology. Humana Press Inc., Totowa, N.J.

46a.Samuels, D. S. Unpublished data

46b.Samuels, D. S., and W. M. Huang. Unpublished data

47. Samuels, D. S., K. E. Mach, and C. F. Garon. 1994. Genetic transformation of the Lyme disease agent Borrelia burgdorferi with coumarin-resistant gyrB. J. Bacteriol. 176:6045-6049.

48. Samuels, D. S., R. T. Marconi, W. M. Huang, and C. F. Garon. 1994. gyrB mutations in coumermycin $\mathrm{A}_{1}$-resistant Borrelia burgdorferi. J. Bacteriol. 176:3072-3075.

49. Schwan, T. G., J. Piesman, W. T. Golde, M. C. Dolan, and P. A. Rosa. 1995. Induction of an outer surface protein on Borrelia burgdorferi during tick feeding. Proc. Natl. Acad. Sci. USA 92:2909-2913.

50. Simpson, W. J., C. F. Garon, and T. G. Schwan. 1990. Analysis of supercoiled circular plasmids in infectious and non-infectious Borrelia burgdorferi. Microb. Pathog. 8:109-118.

51. Southern, E. M. 1975. Detection of specific sequences among DNA fragments separated by gel electrophoresis. J. Mol. Biol. 98:503-517.

52. Steere, A. C., R. L. Grodzicki, A. N. Kornblatt, J. E. Craft, A. G. Barbour, W Burgdorfer, G. P. Schmid, E. Johnson, and S. E. Malawista. 1983. The spirochetal etiology of Lyme disease. N. Engl. J. Med. 308:733-740.

53. Stevenson, B., and S. W. Barthold. 1994. Expression and sequence of outer surface protein $\mathrm{C}$ among North American isolates of Borrelia burgdorferi. FEMS Microbiol. Lett. 124:367-372.

54. Stevenson, B., K. Tilly, and P. A. Rosa. 1996. A family of genes located on four separate 32-kilobase circular plasmids in Borrelia burgdorferi B31. J. Bacteriol. 178:3508-3516.

55. Tanimoto, K., F. Y. An, and D. B. Clewell. 1993. Characterization of the traC determinant of the Enterococcus faecalis hemolysin-bacteriocin plasmid pAD1: binding of sex pheromone. J. Bacteriol. 175:5260-5264.

56. Tilly, K., and B. Stevenson. Unpublished data. 